\title{
NOVEL INTEGRATED PROCESS TO PRODUCE FUELS FROM COAL AND OTHER CARBONACEOUS FEEDSTOCKS
}

\section{TOPICAL REPORT}

Start Date: 2005

End Date: 2009

By

Andrew Lucero

April 2009

Work Performed Under Cooperative Agreement

JSR Task 64 under DE-FC26-98FT40323

For

Bioconversion Technology LLC

Denver, Colorado

And

U.S. Department of Energy

National Energy Technology Laboratory

Morgantown, West Virginia

By

Western Research Institute

Laramie, Wyoming

Kamalendu Das

Task 64 
TABLE OF CONTENTS

Page

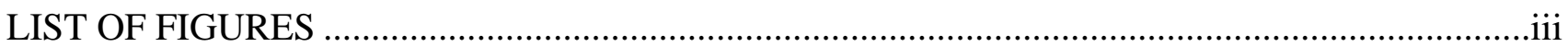

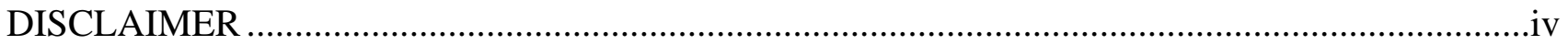

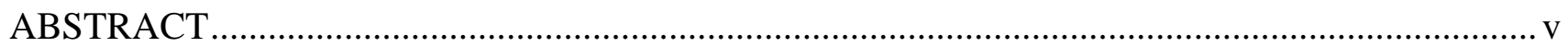

EXECUTIVE SUMMARY …………….................................................................................

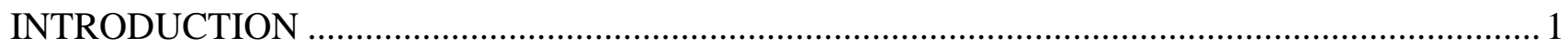

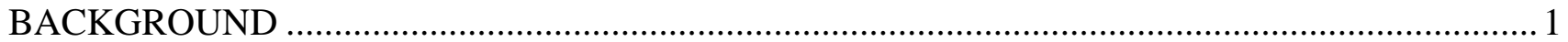

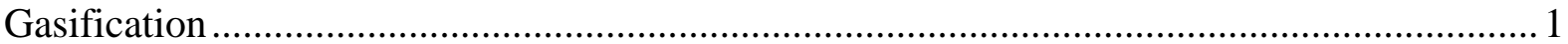

Commercial Gasifier Technologies ……………….............................................................. 2

BioConversion Technology Gasifier ....................................................................................

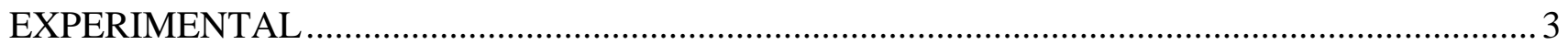

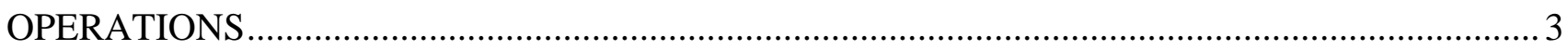

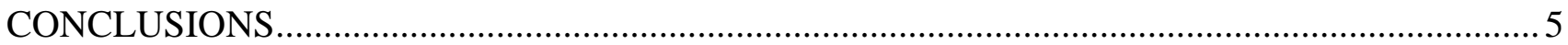




\section{LIST OF TABLES AND FIGURES}

Page

\section{Tables}

1. Typical Synthesis Gas Compositions for Gasifier Operating on Wood Chips ..................................5

2. Average Gas Composition for Gasifier on Coal Feed ..............................................................

\section{Figures}

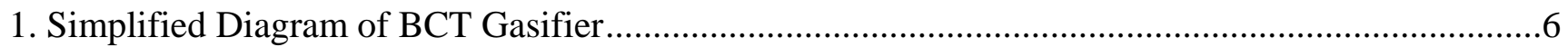

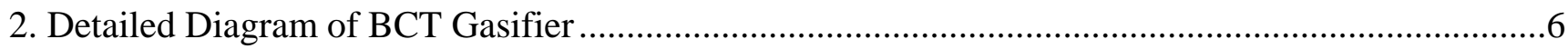

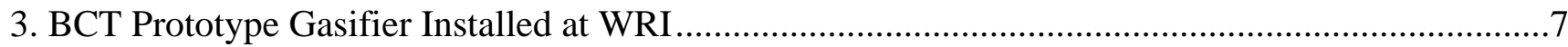

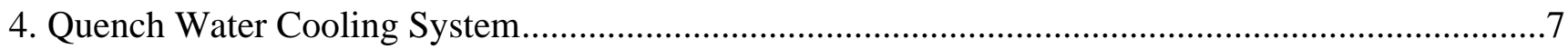

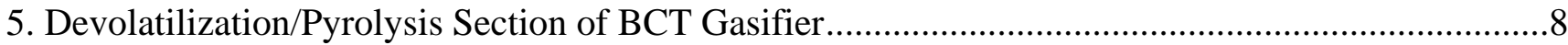

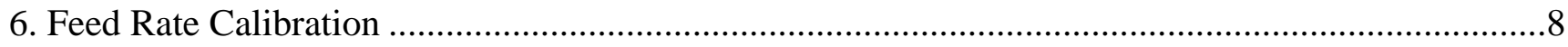

7. Gas Compositions During Gasifier Experiment Using Coal Feed ...............................................9 


\section{DISCLAIMER}

This report was prepared as an account of work sponsored by an agency of the United States Government. Neither the United States Government nor any agency thereof, nor any of their employees makes any warranty, express or implied, or assumes any legal liability or responsibility for the accuracy, completeness, or usefulness of any information, apparatus, product, or process disclosed or represents that its use would not infringe on privately owned rights. Reference herein to any specific commercial product, process, or service by trade name, trademark, manufacturer, or otherwise does not necessarily constitute or imply endorsement, recommendation, or favoring by the United States Government or any agency thereof. The views and opinions of authors expressed herein do not necessarily state or reflect those of the United States Government or any agency thereof. 


\begin{abstract}
BioConversion Technology, LLC has developed a novel gasifier design that produces a clean, medium to high BTU synthesis gas that can be utilized for a variety of applications. The staged, indirectly heated design produces high quality synthesis gas without the need for costly pure oxygen. This design also allows for extreme flexibility with respect to feedstocks (including those with high moisture contents) in addition to high throughputs in a small gasifier footprint.

A pilot scale testing project was proposed to assist BCT with commercializing the process. A prototype gasifier constructed by BCT was transported to WRI for installation and testing. After troubleshooting, the gasifier was successfully operated with both coal and biomass feedstocks. Instrument upgrades are recommended for further testing.
\end{abstract}




\section{EXECUTIVE SUMMARY}

BioConversion Technology, LLC has developed a novel gasifier design that produces a clean, medium to high BTU synthesis gas that can be utilized for a variety of applications. The staged, indirectly heated design produces high quality synthesis gas without the need for costly pure oxygen. This design also allows for extreme flexibility with respect to feedstocks (including those with high moisture contents) in addition to high throughputs in a small gasifier footprint.

A pilot scale testing project was proposed to assist BCT with commercializing the process. A prototype gasifier constructed by BCT was transported to WRI for installation and testing. After

troubleshooting, the gasifier was successfully operated with both coal and biomass feedstocks. Instrument upgrades are recommended for further testing. 


\section{INTRODUCTION}

Over the past few decades, the federal government has supported R\&D on several fronts to find alternative sources of petroleum-based feedstock and to develop new sources of transportation fuels to reduce Nation's dependence on imported oil. Fischer-Tropsch (FT) synthesis is a method of thermochemically producing fuels and chemicals from carbonaceous feedstocks. There are two main processing steps in FT synthesis. The first step involves converting carbonaceous feedstock to synthesis gas in a gasifier (solid feedstocks) or a partial oxidation unit or reformer (gaseous feedstocks). The second step is to convert synthesis gas to products in a pressurized catalytic reactor. The catalyst and operating conditions in the second reactor determine the chemical or fuel product.

A primary disadvantage to FT synthesis is that huge plants are generally required to make them profitable due to the capital costs involved (economies of scale). In the United States it is not clear if feedstocks other than coal and possibly biomass in a few selected locations are present in sufficient quantities at reasonable costs to support FT production of fuels. If the capital and operating costs for these plants can be reduced so that a farmer or a farm cooperative could produce fuels, the economic benefits would shift from large corporations to rural communities - bringing selfsufficiency back to farming. Accomplishing this goal requires radical improvements in efficiencies and costs; however, distributed fuel production would result in a massive increase in the quantity of fuel that could be produced, resulting in equally large displacements of petroleum products. A recent study by Sandia National Laboratory indicated that the U.S. could displace about 1/3 of its gasoline use by 2030 with ethanol. Making farmers and farm communities energy producers not only assists those goals but helps farming economics. Several commercial gasification technologies exist for large scale operations; however, few of these designs are appropriated for distributed applications. Combined with other advanced, the gasifier design described here has the potential to fill a niche for small to medium scale applications, and may help bring the costs for distributed generation of fuels down so that it could be economically viable.

\section{Gasification}

\section{BACKGROUND}

Technologies for converting coal to combustible gas have been in use for nearly two hundred years. The process relies on several main exothermic and endothermic reactions including combustion

hydrogasification

$$
\mathrm{C}+\mathrm{O}_{2} \rightarrow \mathrm{CO}_{2} \quad(-393,790 \mathrm{~kJ} / \mathrm{kgmol}) \text {, }
$$

$$
\mathrm{C}+2 \mathrm{H}_{2} \rightarrow \mathrm{CH}_{4} \quad(-74,900 \mathrm{~kJ} / \mathrm{kgmol}),
$$

the steam-carbon reaction

the Boudouard

$$
\mathrm{C}+\mathrm{H}_{2} \mathrm{O} \rightarrow \mathrm{CO}+\mathrm{H}_{2} \quad(175,440 \mathrm{~kJ} / \mathrm{kgmol}),
$$

reaction 
water-gas shift

$$
\mathrm{C}+\mathrm{CO}_{2} \rightarrow 2 \mathrm{CO} \quad(172,580 \mathrm{~kJ} / \mathrm{kgmol})
$$

and methanation

$$
\mathrm{CO}+\mathrm{H}_{2} \mathrm{O} \rightarrow \mathrm{CO}_{2}+\mathrm{H}_{2} \quad(-2,853 \mathrm{~kJ} / \mathrm{kgmol})
$$

$$
\mathrm{CO}+3 \mathrm{H}_{2} \rightarrow \mathrm{CH}_{4}+\mathrm{H}_{2} \mathrm{O} \quad(-250,340 \mathrm{~kJ} / \mathrm{kgmol})
$$

The combustion reaction generates the heat necessary to drive the endothermic reactions that form synthesis gas. Pyrolysis reactions also contribute to the formation of synthesis gas.

\section{Commercial Gasifer Technologies}

There are several gasification technologies that have been used in commercial applications. These include the GE (Texaco) Entrained Flow Gasifier, the Shell Entrained Flow Gasifier, The Lurgi Dry Ash Gasifier, the British Gas/Lurgi Fixed-Bed Gasifier, the Conoco Phillips E-GAS Entrained Flow Gasifier, and the KRW Fluidized-Bed Gasifier.

The GE gasifier is a single stage entrained-flow (downward flow) slagging gasifier that reacts coal slurry with oxygen. The Shell gasifier is a dry-feed entrained-flow (upward flow) pressurized slagging gasifier. The Lurgi Dry Ash Gasifer is a pressurized dry-ash moving bed (downward flow) gasifier. Steam and oxygen flow counter-current to a moving coal bed. The British Gas/Lurgi gasifier is a pressurized dry-feed fixed-bed slagging gasifier. The E-GAS (formerly Destec) gasifier is a slurry-feed, pressurized, upflow, entrained slagging gasifier that operates in dual stages. Approximately $3 / 4$ of the feed is reacted with oxygen in the bottom stage and the remaining feed reacts with raw synthesis gas in the top stage. The KRW gasifier is a fluidized bed in which coal particles are reacted with oxygen. Both coal and oxygen are then reacted with steam at high temperature. All of these gasifiers require oxygen to produce a synthesis gas suitable for conversion to liquid fuels. The gasifiers differ in the feed characteristics, flow paths, reagent contacting, slagging characteristics, and operating temperatures.

\section{BioConversion Technology Gasifier}

Bioconversion Technology's gasifer is radically different from the above-mentioned gasifiers in that it does not directly contact the feedstock with either air or oxygen. This feature prevents dilution of synthesis gas with nitrogen and eliminates the need for a costly oxygen plant. The design is based on staged, indirectly heated gasification, which allows greatly improved control of the temperature and then the resulting synthesis gas. The gasifier is designed to control the oxidation of the feed material to produce higher quality synthesis gas while reducing carbon dioxide. The intent of the design is to reduce combustion and eliminate the formation of slag. This is accomplished by controlling the temperature of the reactions in distinct stages. In the initial stage, temperature is maintained below $1000^{\circ} \mathrm{F}$ while pyrolysis occurs and available oxygen is utilized. The temperature is then increased prior to contacting the pyrolysis gases and remaining char with superheated steam, 
which is generated by combusting a fraction of the resulting synthesis gas (methane or propane is used for initial start-up). This approach minimizes $\mathrm{CO}_{2}$ concentration in the synthesis gas and allows improved control of the resulting $\mathrm{H}_{2}$ to $\mathrm{CO}$ ratio by varying the steam to carbon ratio in the gasifier. It also allows the gasifier to be extremely flexible with respect to feedstocks including those with high moisture contents (up to $40 \%$ by weight). Figure 1 shows a simplified schematic of the gasifier. Figure 2 shows a drawing from BCT's patent along with descriptions of several of the primary pieces of equipment.

\section{EXPERIMENTAL}

The gasifier was installed in WRI's Advanced Technology Center (Figure 3). Although the main burner is capable of running on both methane and synthesis gas, it was installed with methane feed for the purposes of our experiments. A recirculating water system with an air cooler was installed to supply water for the quenches (Figure 4). It was eventually moved inside the building to simplify freeze protection. The synthesis gas was piped through a flame arrestor to a flare system. Synthesis gas was analyzed with online gas chromatographs.

The gasifier consists of a 4-auger devolatilization/pyrolysis (“devol”) module (Figure 5) close-coupled to a circular reformer coil. There is a steam eductor at the outlet of the devol and a synthesis gas recycle connection at the inlet to the first devol auger. The gas leaving the reformer passes to a cyclone separator inside the fire box, then to a secondary cyclone outside the firebox, then to a water quench followed by filtration. A recycle gas compressor sends quenched syngas through a coalescing filter back to the first devol auger. The unit also has a metering pump that provides water to the steam coil inside the reformer coil. Steam from the steam coil is sent directly to the steam eductor at the outlet of the devol section. Syngas is quenched, compressed, and recycled through a needle valve to the first devol auger. A pressure control regulator maintains system pressure and a positive displacement gas meter measures the product syngas outlet. Key operating parameters are feed rate, firebox temperature, recycle gas rate, and steam flow rate. Feed rate is controlled by an auger driven by an electric motor controlled by a variable frequency drive (VFD). Figure 7 shows the feed rate for wood chips based on the VFD setting. The firebox temperature is controlled by the burner described previously. The recycle gas rate is currently controlled by a needle valve. The steam flow rate is controlled by a water metering pump.

\section{OPERATIONS}

After the gasifier was installed at WRI, the project team focused on a period of troubleshooting and shakedown to ensure that the system could be properly operated for experiments. Several problems were identified and corrected on the flare system and controls. Initial troubleshooting for the gasifier focused on verifying that the various electric components on the system functioned as designed. Several problems, primarily caused during transportation of the unit, were identified and corrected. The primary solenoid controlling the gasifier burner also required replacement. After the burner began operating properly, we found that we could not reach desired 
temperatures on the firebox. To correct this issue we replaced the low pressure house gas line with a higher pressure line that could be regulated anywhere between 3 and 42" W.C. With the modifications, the burner would light, and the fire-box would reach desired temperatures quickly.

Several attempts were made to run the gasifier using wood chips but were unsuccessful due to high pressure differentials. The prototype unit has a tight clearance in the annular gap in the eductor throat, and it was thought that that area was plugged. Initially a boroscope was used to try to find the plugs, but the system, however, had too many sharp turns to thread the boroscope into place. The system was cleaned several times, and all of the plugs causing the high pressure differential pressure were removed by heating the gasifier to about $600 \mathrm{~F}$, and then alternating water and compressed air flow backwards through the system. The water flash-boiled to steam, inducing the mechanical action required to remove all of the obstructions. The steam and compressed air were removed via the open ports left by removing the devol augers.

Several successful runs were then completed operating the gasifier on wood chips. All were performed at VFD settings of about $15 \mathrm{~Hz}$, or a mass feed rate of about $10 \mathrm{lbs} / \mathrm{hr}$. Higher settings were attempted, but always resulted in plugging the mixing eductor. Typical compositions of the resulting synthesis gas are shown in Table 1 (data at $1950 \mathrm{~F}$ control temperature). During the course of testing, some interesting trends in gas composition were observed:

- Increasing feed rates increased $\mathrm{CO} / \mathrm{H}_{2}$ ratio towards $\mathrm{CO}$. Increasing feed rates also increased methane and higher order hydrocarbon concentrations.

- Increasing water feed rates had nearly no effect on $\mathrm{CO} / \mathrm{H}_{2}$ ratio, but did increase methane and higher order hydrocarbon concentrations. It is estimated that this effect is due to the reduced reforming temperature.

- Lower firebox control temperatures (1650 F was lowest operated) increased methane (and $\mathrm{C} 2+$ ) concentration considerably. Methane concentrations as high as $14 \%$ were recorded during lower temperature operations.

- Higher firebox control temperatures (2000 F was highest operated) significantly reduced hydrocarbon concentrations.

During the project, a single experiment was successfully completed on coal feed. Earlier attempts were unsuccessful due to the plugging problems described earlier. Coal rates were set at 15 $\mathrm{lbs} / \mathrm{hr}$, but actual feed rates were much higher. It appears that the particle size (1/8" to 1/16" nominal) was too small, and the recycle gas flow was forcing the feed through the system at a higher rate than the auger set-point. Gas compositions were recorded at regular intervals and are presented in Figure 7. The variations in nitrogen concentration are due to purge gas when the system was opened at a regular interval to fill the feed hopper. The average synthesis gas composition for the run is presented in Table 2. 
Table 1. Typical Synthesis Gas Compositions for Gasifier Operating On Wood Chips.

\begin{tabular}{|l|c|}
\hline Gas Component & $\begin{array}{c}\text { Normalized } \\
\text { Concentration } \\
\text { mol\% }\end{array}$ \\
\hline $\mathrm{H} 2$ & $45.1 \%$ \\
\hline $\mathrm{O} 2$ & $0.0 \%$ \\
\hline $\mathrm{N} 2$ & $0.7 \%$ \\
\hline $\mathrm{CH} 4$ & $7.0 \%$ \\
\hline $\mathrm{CO}$ & $41.0 \%$ \\
\hline $\mathrm{CO} 2$ & $5.0 \%$ \\
\hline Ethylene & $0.4 \%$ \\
\hline Ethane & $0.0 \%$ \\
\hline Propane & $0.6 \%$ \\
\hline Benzene & $0.2 \%$ \\
\hline Total & $100 \%$ \\
\hline
\end{tabular}

Table 2. Average Gas Composition for Gasifier on Coal Feed.

\begin{tabular}{|l|c|}
\hline Gas Component & $\begin{array}{c}\text { Normalized } \\
\text { Concentration } \\
\text { mol\% }\end{array}$ \\
\hline $\mathrm{H} 2$ & $49.1 \%$ \\
\hline $\mathrm{O} 2$ & $0.0 \%$ \\
\hline $\mathrm{N} 2$ & $3.0 \%$ \\
\hline $\mathrm{CH} 4$ & $9.1 \%$ \\
\hline $\mathrm{CO}$ & $28.1 \%$ \\
\hline $\mathrm{CO} 2$ & $10.7 \%$ \\
\hline & $100 \%$ \\
\hline
\end{tabular}

\section{CONCLUSIONS}

BCT has designed a unique gasifier that should have applications for distributed energy generation and fuel production. After a somewhat challenging period of troubleshooting and learning its operation, WRI personnel successfully operated the gasifier on both biomass and coal feedstocks. Prior to transporting the gasifier to WRI, BCT had successfully operated the unit on a variety of feedstocks including rice hulls, animal manure, several types of biomass, and several types of coal. They have also successfully scaled the design to construct 5 ton per day and 50 ton per day gasifiers. Now that the prototype unit is operating at WRI, several upgrades are recommended for further experiments. A mass flow meter on the natural gas feed would greatly help attempts to develop an energy balance for the unit. Based on experience operating the gasifier, flow-meters are needed on the syngas recycle stream and on the water feed to improve control of operations. An improved product gas flow-meter would also be beneficial. There are also several locations where pressure and temperature measurements are needed. Overall, the unit has proven capable of producing high quality synthesis gas without requiring pure oxygen. A few instrument upgrades are recommended to improve understanding of its operations. 
Feed

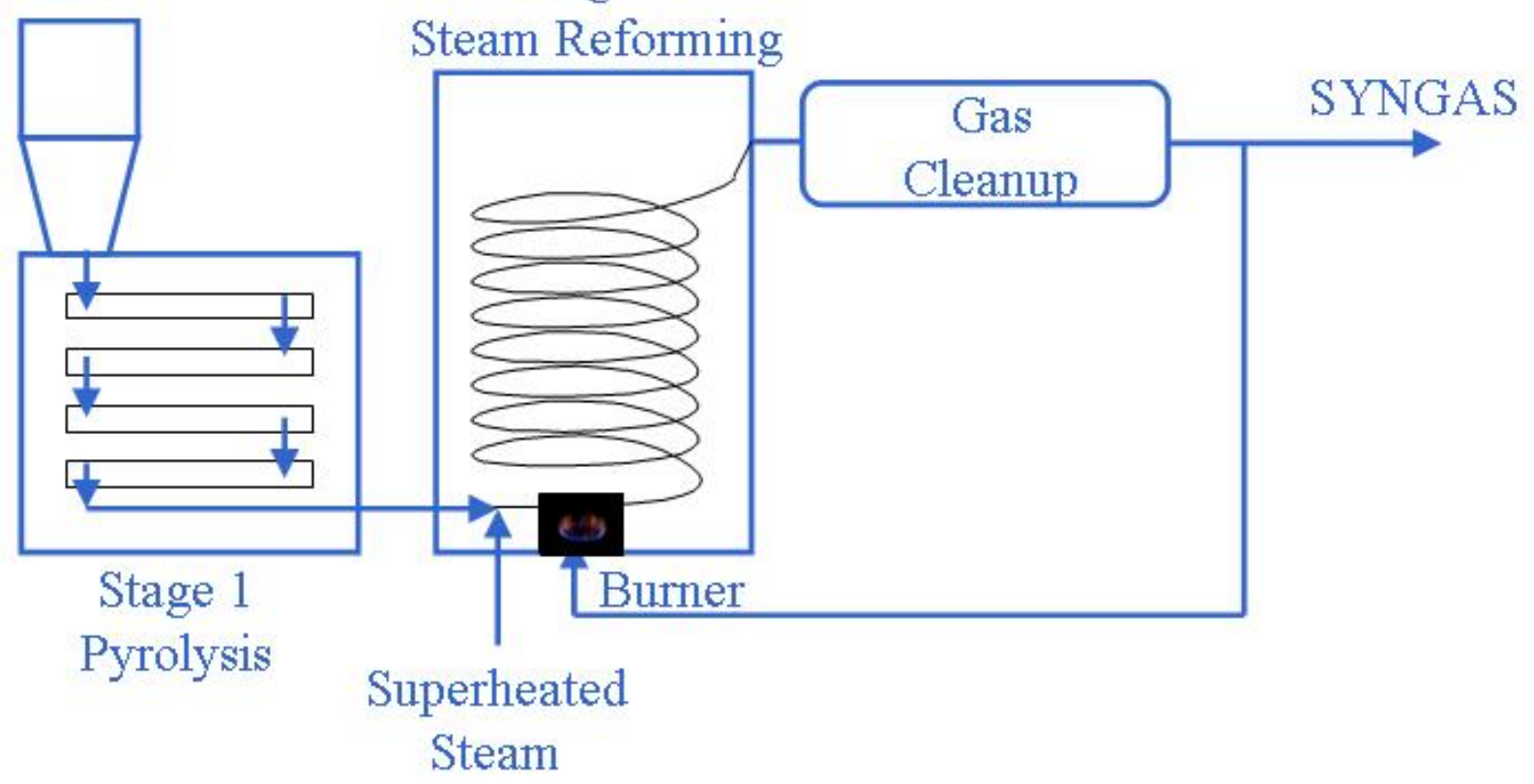

Figure 1. Simplified Diagram of BCT Gasifier

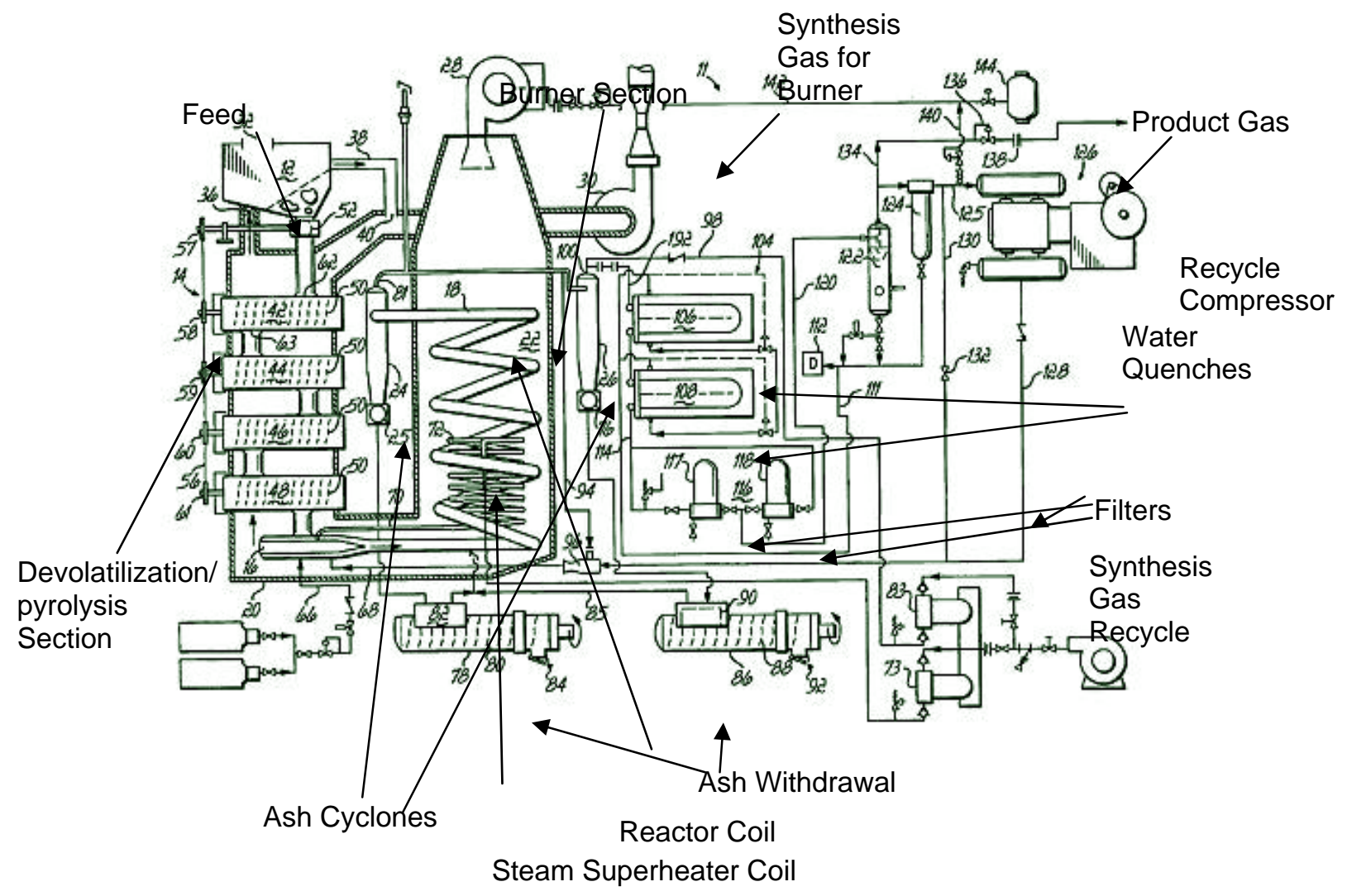

Fiøıre 2. Detailed Diagram of BC.T Gasifier 


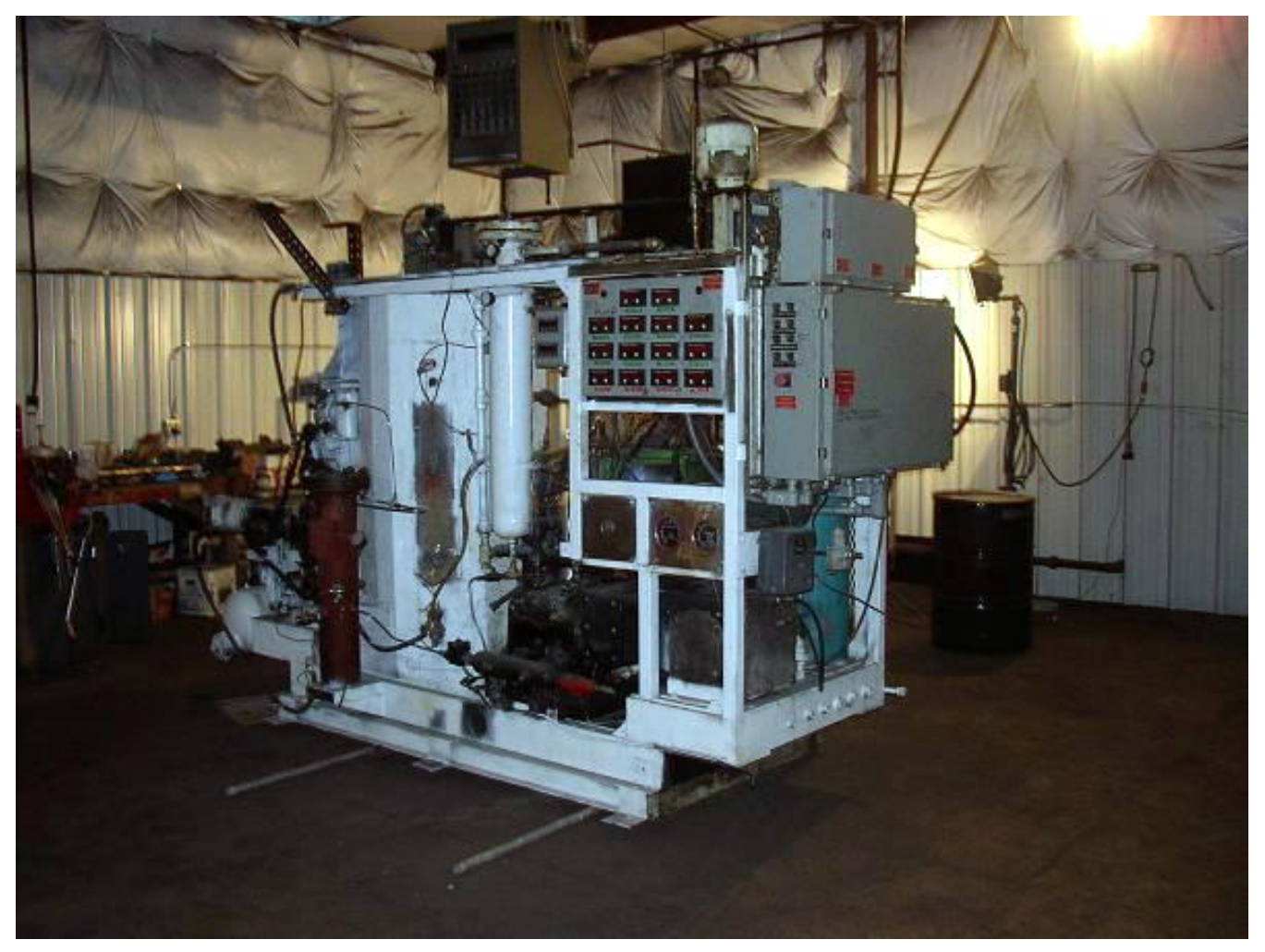

Figure 3. BCT Prototype gasifier installed at WRI

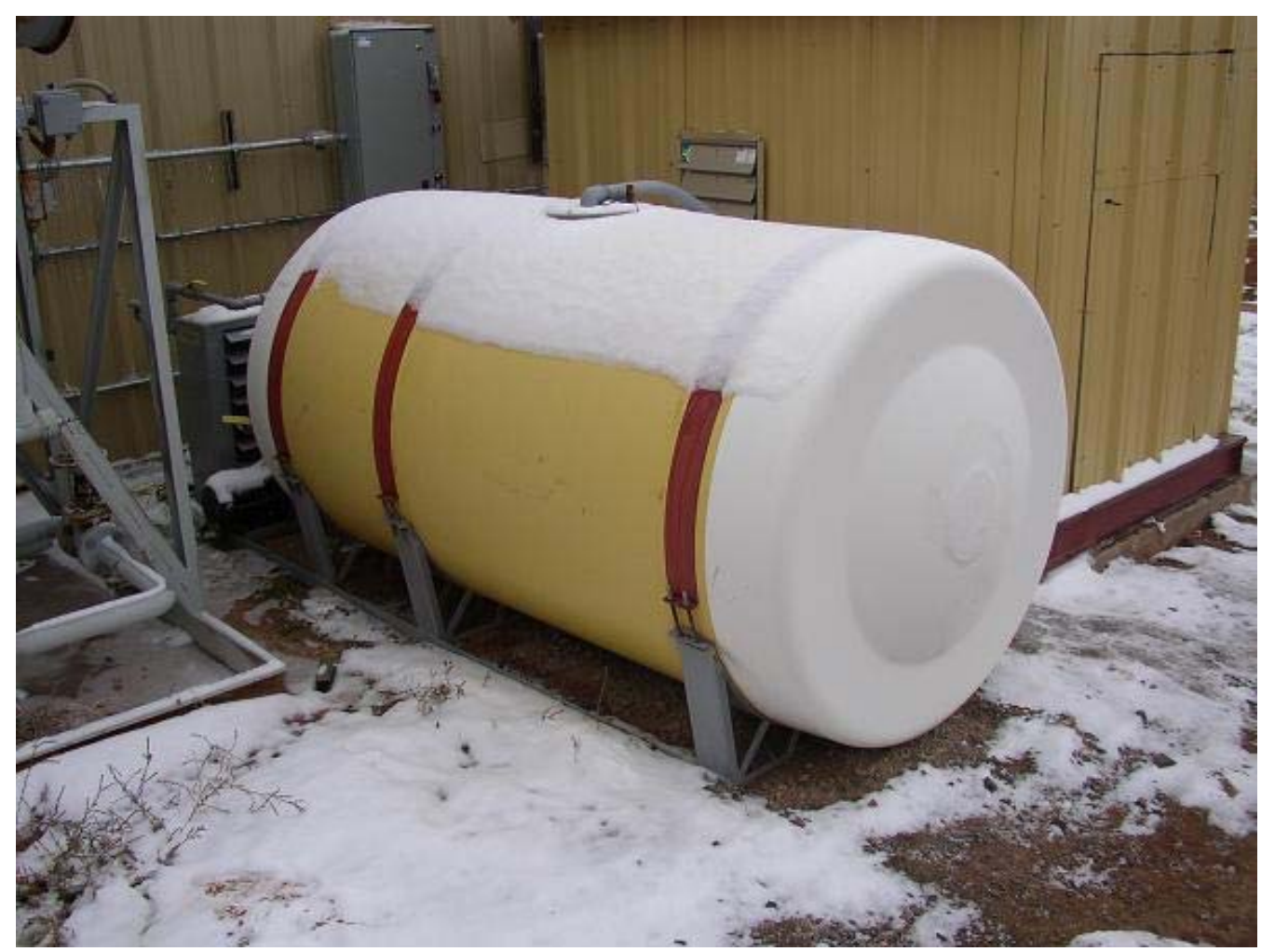

Figure 4. Quench water cooling system 


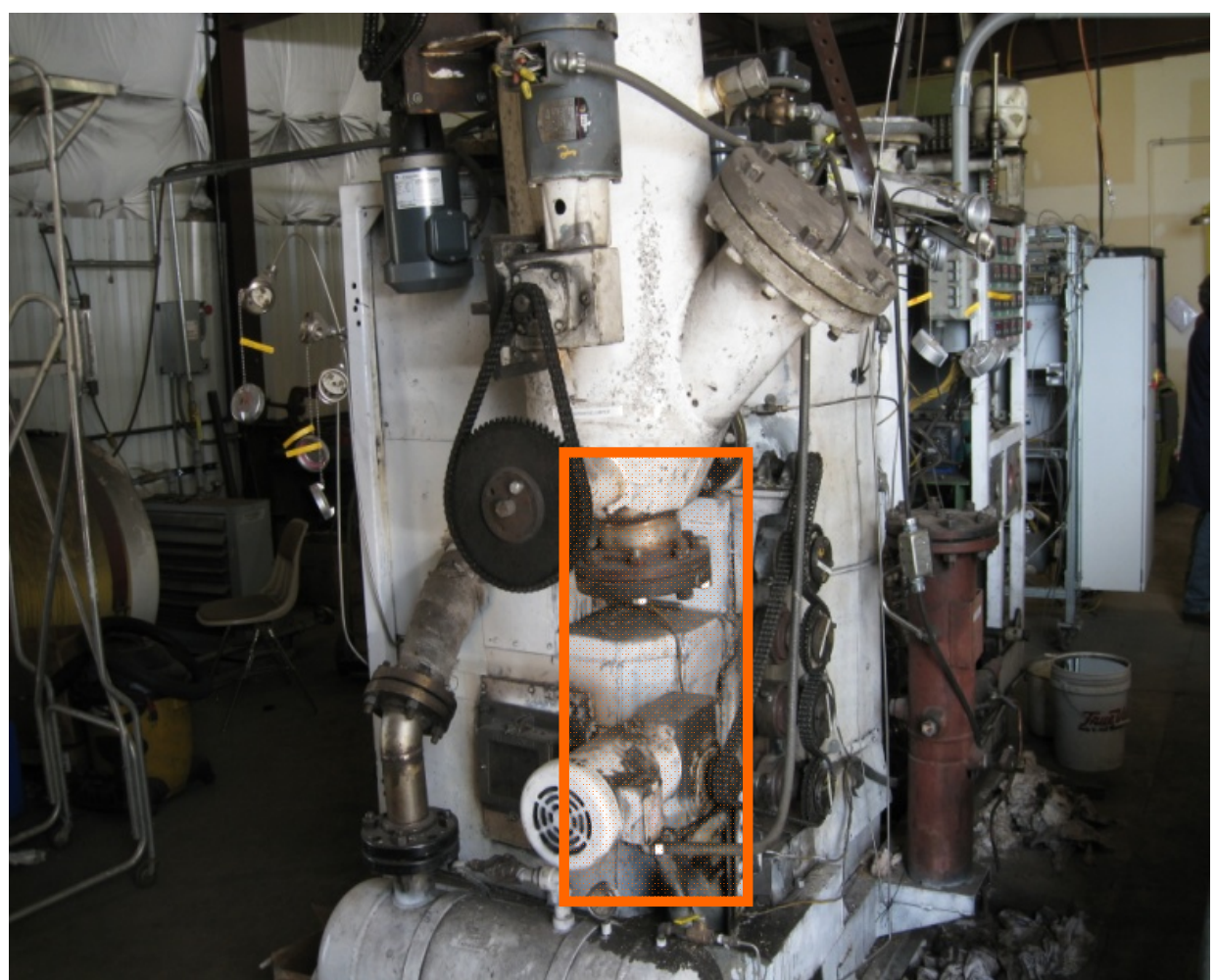

Figure 5. Devolatilization/Pyrolysis Section of BCT Gasifier

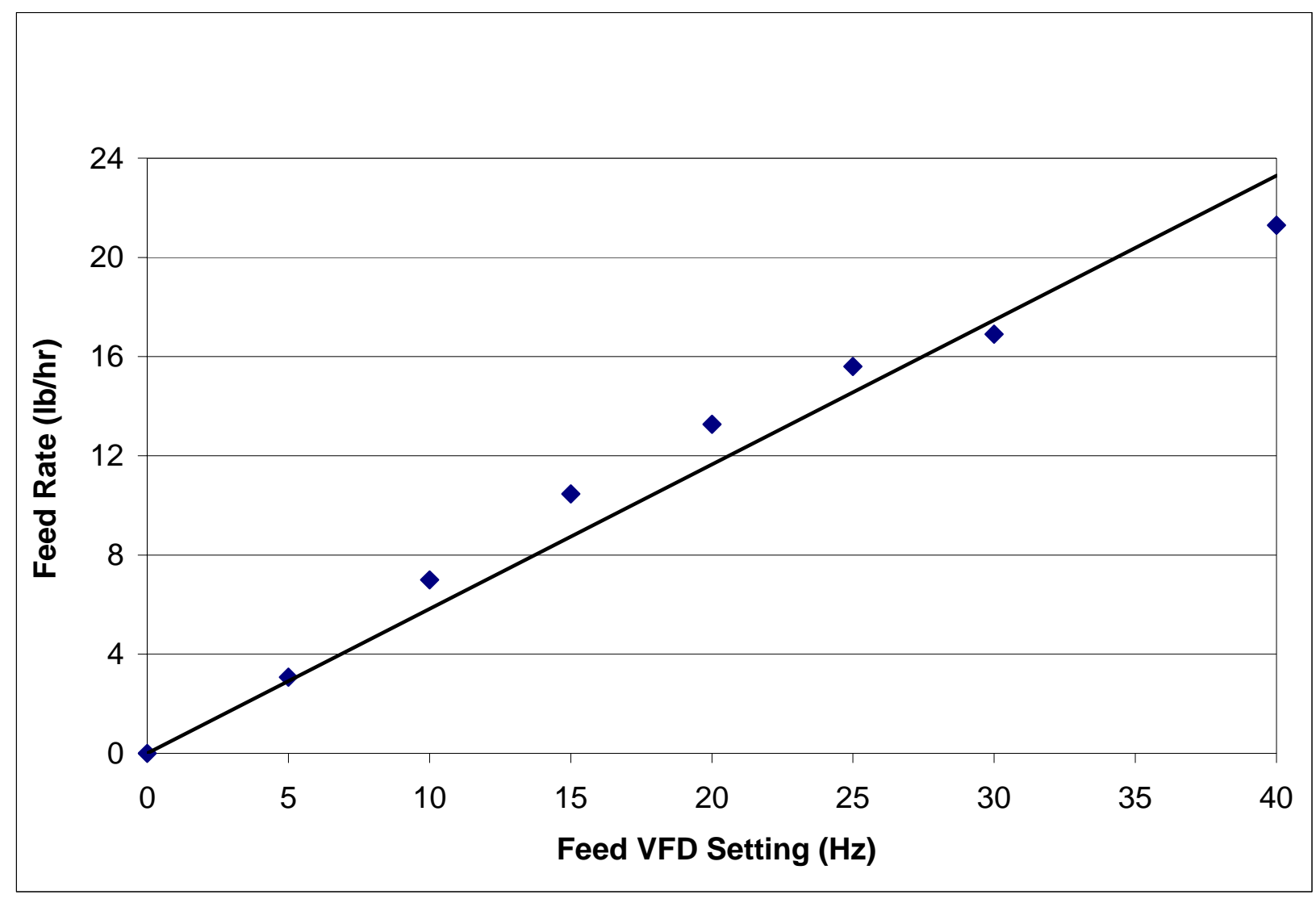

Figure 6. Feed Rate Calibration 


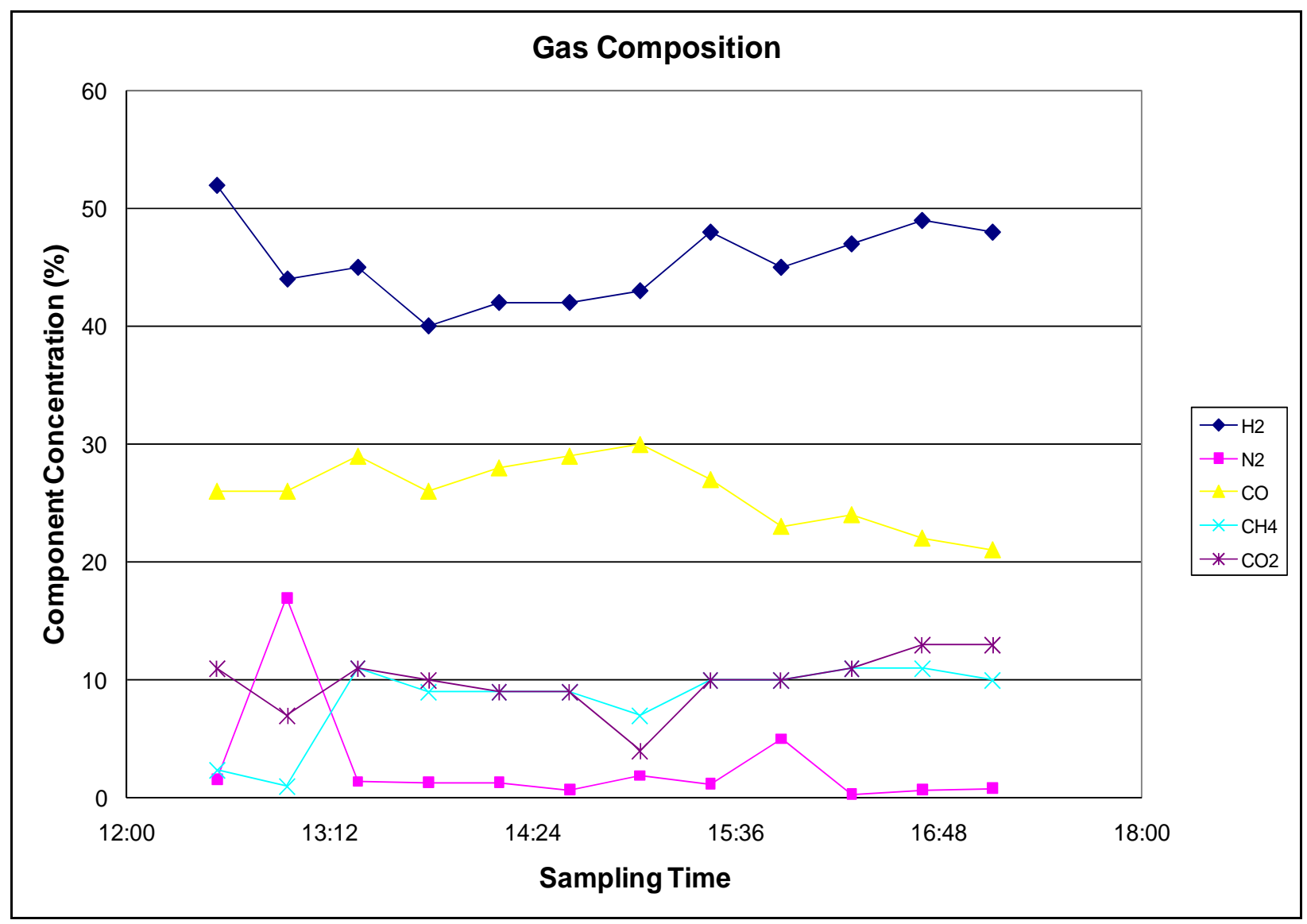

Figure 7. Gas Compositions during Gasifer Experiment Using Coal Feed 